\title{
An unexpected finding in a patient with a DDDR pacemaker
}

\author{
A. Bohm • R. G. Kiss • G. Z. Duray
}

Published online: 5 April 2014

(C) The Author(s) 2014. This article is published with open access at Springerlink.com

A 77-year-old female patient with sinus bradycardia and left bundle branch block was implanted with a DDD Biotronik Kairos DR pacemaker in 1999, then a replacement for depleted battery was performed in 2007 (Biotronik Axios DR). During our regularly scheduled follow-ups, we found the atrial and ventricular sensing/pacing function to be satisfactory: P: $3.6 \mathrm{mV}, \mathrm{R}: 9.9 \mathrm{mV}$, atrial threshold: $0.7 \mathrm{~V} / 0.4 \mathrm{~ms}$, ventricular threshold: $0.5 \mathrm{~V} / 0.4 \mathrm{~ms}$. Parameters were set as follows: basic rate: $60 \mathrm{bpm}$, hysteresis: $-10 \mathrm{bpm}$, dynamic $\mathrm{AV}$ delay: $225 \mathrm{~ms}$, sense compensation: $-45 \mathrm{~ms}$, atrial sensitivity: $1 \mathrm{mV}$, and ventricular sensitivity: $5 \mathrm{mV}$. During the latest follow-up (14 years after the first implantation), the following recording was made (Fig. 1). What would be your interpretation of this recording?

Answer

You will find the answer elsewhere in this issue.

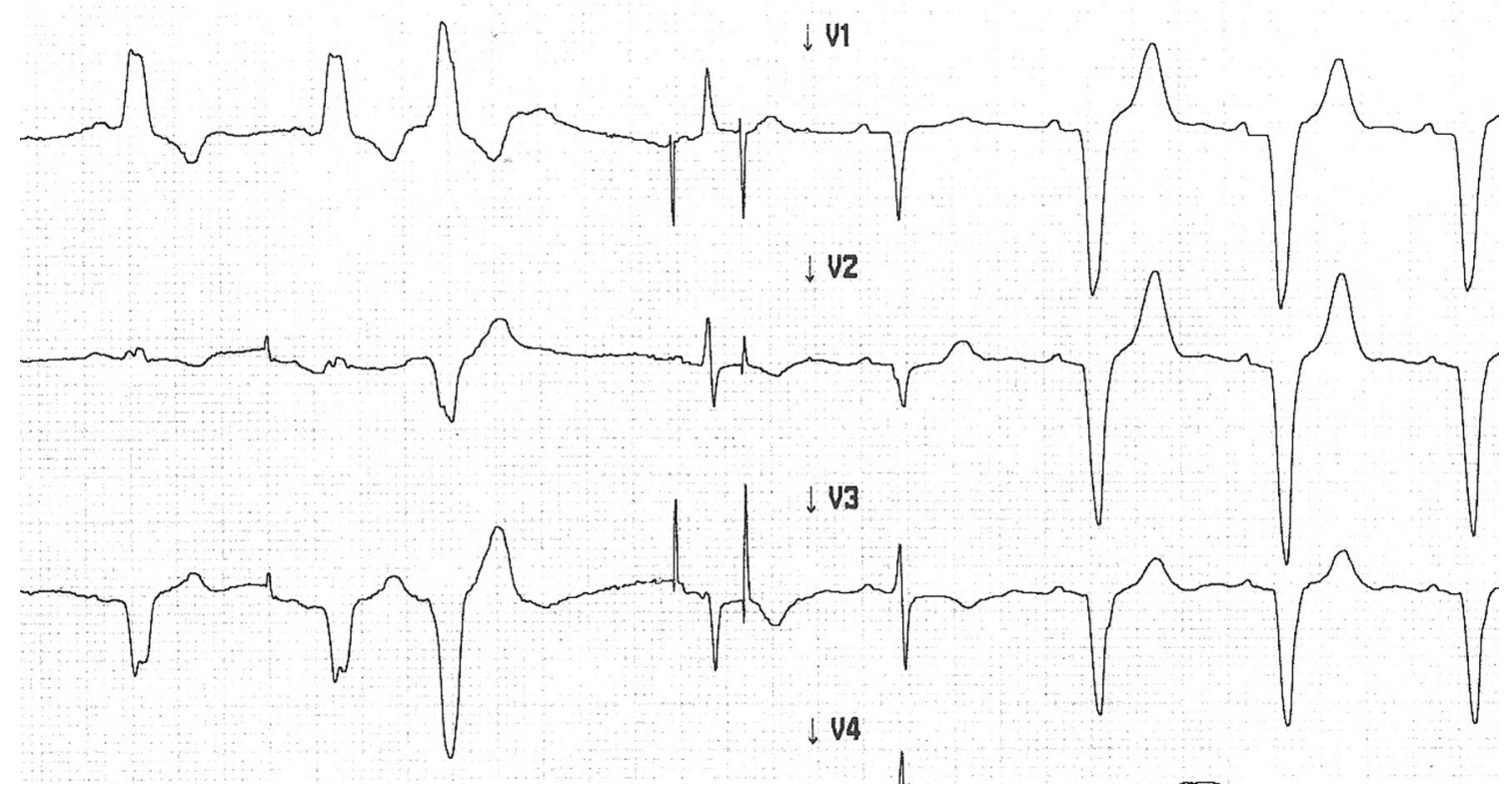

Fig. 1 Ventricular sensing failure, when the QRS is narrow

A. Bohm $(\bowtie) \cdot$ R. G. Kiss $\cdot$ G. Z. Duray

Department of Cardiology, Military Hospital, Róbert K körút 44, Budapest 1134, Hungary

e-mail: abohm@freemail.hu
Open Access This article is distributed under the terms of the Creative Commons Attribution License which permits any use, distribution, and reproduction in any medium, provided the original author(s) and the source are credited. 